\title{
The Buss-Perry Aggression Questionnaire: Construct validity and gender invariance among Argentinean adolescents
}

\section{Cuestionario de Agresión de Buss-Perry: validez de constructo e invarianza de género en adolescentes argentinos}

\author{
Cecilia Reyna \\ Universidad Nacional de Córdoba \\ Consejo Nacional de Investigaciones Cientificas y Técnicas Argentina \\ Maria Gabriela Lello Ivacevich \\ Universidad Nacional de Córdoba \\ Anahi Sanchez \\ Universidad Nacional de Córdoba \\ Silvina Brussino \\ Universidad Nacional de Córdoba \\ Consejo Nacional de Investigaciones Científicas y Técnicas Argentina
}

\begin{abstract}
The Aggression Questionnaire (Buss \& Perry, 1992) is one of the most used instruments to assess aggression; it includes 29 items grouped into 4 factors. Furthermore, a reduced version of 12-item has been proposed (Bryant \& Smith, 2001), and it has also been examined by several researchers. Nevertheless, Latin-American samples have rarely been included. In this study, exploratory and confirmatory models were evaluated among a sample of adolescents from Cordoba, Argentina $(N=371)$. Moreover, internal consistency and gender invariance were examined. A 2 -factor structure resulted in the exploratory analysis, while 2- and 4-factor (short and long versions) structures showed acceptable fits in confirmatory analysis. In general, internal consistency was acceptable, and gender invariance was supported. Implications and limitations are discussed.
\end{abstract}

Key words:Aggression Questionnaire; adolescents; factor structure; gender invariance.

\section{RESUMEN}

El Cuestionario de Agressión (Buss \& Perry, 1992) es uno de los instrumentos más utilizados para evaluar la aggression, comprende 29 ítems agrupados en 4 factores. Otros autores han propuesto una versión reducida de 12 ítems (Bryant \& Smith, 2001), la cual ha sido examinada por diversos investigadores. Sin embargo, dichos estudios en raras ocasiones han comprendido muestras latinoamericanas. En este estudio, se evalúan modelos exploratorios y confirmatorios en una muestra de adolescentes de la ciudad de Córdoba, Argentina $(N=371)$. Además, se examina la consistencia interna y la invarianza de género. En el análisis factorial exploratorio, la estructura bifactorial ofreció el mejor ajuste; mientras que estructuras de 2 y 4 factores (versiones larga y corta) mostraron ajustes aceptables en análisis confirmatorios. En términos generales, la consistencia interna fue aceptable. Los resultados avalan la invarianza de género. Se discuten las implicancias y limitaciones.

Palabras clave:Cuestionario de Agresión; adolescentes; estructura factorial; invarianza de género.

Artículo recibido/Article received:Septiembre142011/September 142011,Artículo aceptado/Article accepted:Septiembre 23 2011/September 23 2011 Dirección correspondencia/Mail Address:

Cecilia Reyna, Laboratorio de Psicología Cognitiva, Facultad de Psicología, UNC, Ciudad Universitaria - (5000) Córdoba, Argentina. E-mail: ceciliareyna@ gmail.com/ cereyna@psyche.unc.edu.ar

INTERNATIONAL JOURNAL OF PSYCHOLOGICAL RESEARCH esta incluida en PSERINFO, CENTRO DE INFORMACION PSICOLOGICA DE COLOMBIA,OPEN JOURNAL SYSTEM, BIBLIOTECA VIRTUAL DE PSICOLOGIA (ULAPSY-BIREME), DIALNET y GOOGLE SCHOLARS. Algunos de sus articulos aparecen en SOCIAL SCIENCE RESEARCH NETWORK y está en proceso de inclusion en diversas fuentes y bases de datos internacionales. INTERNATIONAL JOURNAL OF PSYCHOLOGICAL RESEARCH is included in PSERINFO, CENTRO DE INFORMACIÓN PSICOLÓGICA DE COLOMBIA, OPEN JOURNAL SYSTEM, BIBLIOTECA VIRTUAL DE PSICOLOGIA (ULAPSY-BIREME), DIALNET and GOOGLE SCHOLARS. Some of its articles are in SOCIAL SCIENCE RESEARCH NETWORK, and it is in the process of inclusion in a variety of sources and international databases. 
International Journal of Psychological Research, 2011.Vol. 4. No. 2. ISSN impresa (printed) 2011-2084

ISSN electrónica (electronic) 2011-2079

\section{INTRODUCTION}

Aggression is a personality trait that is related to antisocial behavior. Anderson and Bushman (2002) have offered an integrative explanatory framework for aggression, in which cognitive, emotional and personal variables interact with situational and environmental factors. One of the most used instruments for its study is the Aggression Questionnaire constructed by Buss and Perry (1992), which comprises 29 items grouped into four factors: physical aggression, verbal aggression, anger and hostility. The first two factors represent the instrumental component. Anger implies physiological activation and represents the emotional component, while hostility involves feelings of opposition and injustice thus representing the cognitive component. Apparently, anger acts as a psychological bridge connecting instrumental and cognitive components. In the original study, the male participants were more aggressive considering the full scale, and also the physical dimension. In the same direction, minor but significant differences were observed on verbal aggression and hostility subscales. However, men and women reported similar levels of anger (Buss \& Perry, 1992).

This questionnaire has been validated in different countries and translated into several languages, including Spanish, Italian, Dutch, Japanese, German, French, Slovak and Greek. Not all those studies have supported the 4-factor structure originally proposed. Moreover, gender differences have not always been observed in the same dimensions.

Although most studies support a tetra-factor structure there are discrepancies with regard to the items included in each factor and the factor loadings and/or regression coefficients (e.g., García-León, Reyes, Vila, Pérez, Robles, \& Ramos, 2002; Rodríguez, Peña, y Graña, 2002). Moreover, some researchers have found better fits with bi-factor (Maxwell, 2007; Williams, Boyd, Cascardi, \& Poythress, 1996), tri-factor (Sommantico, Osorio, Parrello, De Rosa, \& Donizetti, 2008), or penta-factor structures (Castillón, Ortiz, y Vieco, 2004). Furthermore, Bryant and Smith (2001) have proposed a 12-item version based on intensively exploratory and confirmatory studies. That reduced version has shown an improvement fit in the Bryant and Smith's study, and it has also presented acceptable psychometric properties in other studies (Ang, 2007; Gallardo, Kramp, García, Pérez, \& Andrés, 2006; Maxwell, 2007; Morales, Codorniu, \& Vigil, 2005; Tremblay \& Ewart, 2005; Vitoratou, Ntzoufras, Smyrnis, \& Stefanis, 2009).

One issue extensively investigated in relation to aggression is gender differences. In this regard, many studies have inquired about that by means of the Aggression Questionnaire. Males have consistently been
Reyna, C., Lello, M. G., Sanchez, A., \& Brussino, S. (2011). The Buss-Perry Aggression Questionnaire: Construct validity and gender invarianceamong Argentinean adolescents. International Journal of Psychological Research, 4(2), $30-37$.

found to be more physically aggressive than women (e.g., Andreu, Peña, \& Graña, 2002; Buss \& Perry, 1992; Tremblay \& Ewart, 2005; for a review see Archer, 2004). However, evidence is less clear in other dimensions. Studies reporting gender differences on verbal aggression have shown a mixed pattern and small size effects (e.g., Ang, 2007; Buss \& Perry, 1992; García-León et al., 2002; Meesters, Muris, Bosma, Schouten, \& Beuving, 1996; Sommantico et al., 2008; Vitoratou et al., 2009). Regarding to anger, differences have not always been observed, and where gender differences have been found, it has been in the women direction (e.g., Andreu et al., 2002; Santisteban, Alvarado, \& Recio, 2007; Sommantico et al., 2008; von Collani \& Werner, 2005). Finally, gender differences in hostility have rarely been reported, with few and mixed differences (e.g., Andreu et al., 2002; Buss \& Perry, 1992; Maxwell, 2007).

Nonetheless, the study of gender differences only makes sense if measurement invariance is confirmed, which implies that different groups interpret a construct in a similar way (Byrne \& Watkins, 2003). The structure of the Aggression Questionnaire has shown to be invariant or partially invariant with respect to gender, culture and age (Ang, 2007; Bryant \& Smith, 2001; Fossati, Maffei, Acquarini, \& Di Ceglie, 2003; Santisteban et al., 2007; Vitoratou et al., 2009).

\section{Purpose of research}

Previous findings about the Aggression Questionnaire are not consistent with regard to the factorial structure. Besides, gender differences have not always been observed along all dimensions. Based on that, and taking into account the need for a reliable and valid instrument to measure aggression among Argentinean adolescents, in this study we proposed to examine factor structure of the Aggression Questionnaire through exploratory and confirmatory models, testing also internal consistency. Furthermore, we proposed to evaluate gender invariance along three factorial models.

\section{METHOD}

\section{Participants}

The sample consisted of 371 adolescentsaged 12 to 19 years $(M=14.89 ; \quad S D=1.97)$ attending to two public schools in the city of Cordoba (Argentina). Men were $134(M=14.96$ years old, $S D=1.94)$ and women were $237(M=14.86$ years old, $S D=1.99)$. Selection was not random due to the accessibility to the population of interest. Participation was voluntary and anonymous. 
International Journal of Psychological Research, 2011.Vol. 4. No. 2. ISSN impresa (printed) 2011-2084

ISSN electrónica (electronic) 2011-2079

\section{Measure and procedure}

The Aggression Questionnaire (Buss \& Perry, 1992) is a 29-item scale that measure four aspects of human aggression. Two Spanish versions have been published (Andreu et al., 2002; Santisteban \& Alvarado, 2009). For this study, a pilot study was carried out in order to obtain an understandable version to Argentinean adolescents. The sentences of both Spanish versions were assessed by 5 adolescents who had to indicate the words or phrases that they did not understand, and in those cases they had to do suggestions. The final version was defined by the researchers; minimum modifications were applied (see Appendix). Participants were asked to rate each item using a 5-point Likert-type scale ( $1=$ uncharacteristic of me, $5=$ very characteristic of me). The questionnaire was taken collectively in each course during a normal class day.

\section{Analysis}

First, data were studied using usual exploratory techniques (Hair, Black, Babin, \& Anderson, 2009). Second, an exploratory factor analysis (EFA) was conducted. Third, three models were evaluated through confirmatory factor analyses: A-model: 2-factor from EFA (27 items); B-model: 4-factor based on Buss and Perry (1992, 29 items); and C-model: 4-factor based on Bryant and Smith (2001, 12 items). Also, reliability was tested for each model. Finally, invariance gender was evaluated. For each of the models previously considered a hierarchical set of steps was carried out (Byrne \& Stewart, 2006). In particular, a base model was tested separately for each gender, and then configural, metric and strong invariance were examined (Jöreskog \& Sörbom, 2006). Analyses were conducted using the following software: SPSS 18, LISREL 8.8, and R 2.11.

\section{RESULTS}

An initial analysis showed no univariate or multivariate atypical cases (Hair et al., 2009). Across variables, items presented adequate $( \pm 1)$ or acceptable $( \pm 1.6)$ values for asymmetry and kurtosis (Table 1$)$.

\section{Exploratory factor analysis}

We used a principal axis factoring method in the same way that studies of the original version. The KaiserMayer-Olkin (KMO) measure of sampling adequacy was 0.884 , and Bartlett's test of sphericity was significant $\left(\chi^{2}\right.$ approx. $(406, N=371)=2753.699, p<.000)$, which supported the factorial study. An initial solution suggested 8 factors to be retained with eigenvalues greater than 1 that accounted for $55.61 \%$ of the total variance. However, the screeplot and Horn's parallel analysis suggested retaining 2
Reyna, C., Lello, M.G., Sanchez, A., \& Brussino, S. (2011).The Buss-Perry Aggression Questionnaire: Construct validity and gender invariance among Argentinean adolescents. International Journal of Psychological Research, 4(2), $30-37$.

factors. Consequently, solutions from 2 to 4 factors were analyzed, looking for the most parsimonious and theoretical relevant structure.Oblimin rotation was used because the factors were assumed to be correlated. The Solution with 2 factors was selected: Factor 1 included items of Physical Aggression, Verbal Aggression, and Anger; and Factor 2 included items of Hostility, Verbal Aggression, and Anger. Items 3 and 24 showed low communality and factor loading, so they were not included in posterior analysis (Table 1).

Table 1.Descriptive statistics and factor structure of the Aggressive Questionnaire.

\begin{tabular}{|c|c|c|c|c|c|c|}
\hline & \multirow{2}{*}{$M$} & \multirow{2}{*}{$S D$} & \multirow{2}{*}{ Skewness } & \multirow{2}{*}{ Kurtosis } & \multicolumn{2}{|c|}{ Configurationalmatrix } \\
\hline & & & & & Factor 1 & Factor 2 \\
\hline Item 1 & 2.15 & 1.23 & 0.92 & -0.05 & 0.637 & \\
\hline Item 5 & 2.69 & 1.54 & 0.36 & -1.34 & 0.664 & \\
\hline Item 9 & 3.16 & 1.60 & -0.06 & -1.57 & 0.726 & -0.19 \\
\hline Item 13 & 1.87 & 1.25 & 1.32 & 0.58 & 0.575 & \\
\hline Item 17 & 2.80 & 1.57 & 0.27 & -1.46 & 0.539 & \\
\hline Item 21 & 2.27 & 1.51 & 0.83 & -0.83 & 0.617 & \\
\hline Item 24 & 3.59 & 1.56 & -0.60 & -1.21 & & -0.117 \\
\hline Item 27 & 1.78 & 1.27 & 1.58 & 1.22 & 0.585 & \\
\hline Item 29 & 2.19 & 1.47 & 0.91 & -0.65 & 0.399 & 0.234 \\
\hline Item 2 & 2.77 & 1.28 & 0.44 & -0.81 & 0.373 & 0.183 \\
\hline Item 6 & 2.56 & 1.24 & 0.59 & -0.58 & 0.129 & 0.339 \\
\hline Item 10 & 2.99 & 1.40 & 0.14 & -1.26 & 0.418 & 0.104 \\
\hline Item 14 & 2.45 & 1.31 & 0.69 & -0.60 & 0.41 & 0.23 \\
\hline Item 18 & 1.95 & 1.34 & 1.24 & 0.21 & 0.304 & 0.272 \\
\hline Item 3 & 3.46 & 1.39 & -0.29 & -1.22 & 0.204 & 0.142 \\
\hline Item 7 & 3.35 & 1.39 & -0.17 & -1.30 & & 0.375 \\
\hline Item 11 & 3.26 & 1.42 & -0.17 & -1.27 & 0.251 & 0.467 \\
\hline Item 15 & 2.37 & 1.37 & 0.53 & -1.04 & 0.382 & \\
\hline Item 19 & 2.31 & 1.39 & 0.78 & -0.64 & 0.336 & 0.289 \\
\hline Item 22 & 2.61 & 1.48 & 0.44 & -1.22 & 0.246 & 0.429 \\
\hline Item 25 & 2.59 & 1.53 & 0.50 & -1.24 & 0.178 & 0.333 \\
\hline Item 4 & 1.63 & 0.91 & 1.32 & 0.71 & & 0.321 \\
\hline Item 8 & 3.25 & 1.49 & -0.19 & -1.38 & & 0.378 \\
\hline Item 12 & 2.81 & 1.51 & 0.27 & -1.36 & & 0.575 \\
\hline Item 16 & 2.62 & 1.44 & 0.43 & -1.14 & & 0.628 \\
\hline Item 20 & 2.49 & 1.49 & 0.55 & -1.13 & & 0.468 \\
\hline Item 23 & 3.48 & 1.45 & -0.39 & -1.23 & & 0.431 \\
\hline Item 26 & 2.87 & 1.51 & 0.22 & -1.42 & & 0.619 \\
\hline Item 28 & 3.02 & 1.49 & 0.07 & -1.42 & & 0.368 \\
\hline
\end{tabular}

International Journal of Psychological Research 
International Journal of Psychological Research, 2011.Vol. 4. No. 2. ISSN impresa (printed) 2011-2084

ISSN electrónica (electronic) 2011-2079

\section{Confirmatory factor analysis}

Maximum likelihood method was used. Correlations were allowed between errors within each subscale, and factors were also correlated. The following goodness-of-fit measures were considered: a) absolute fit indexes: chi-square statistic, goodness of fit index (GFI) and adjusted GFI (AGFI), and standardized root-meansquare residual (SRMR); b) comparative fit indexes: comparative fit index (CFI) and non-normed fit index (NNFI); and c) parsimonious fit indexes: mean square error of approximation (RMSEA), parsimony normed fit index (PNFI), parsimony goodness of fit index (PGFI), and Akaike information criteria (AIC) (for further explanations see Brown, 2006; Hu \& Bentler, 1999; Schumacker $\&$ Lomax, 2004). While the $\chi^{2}$ statistic indicates the absolute fit of the model, it is sensitive to sample size and violations of multivariate normality assumption; hence it is recommended that other indices of adjustment are also considered.
Reyna, C., Lello, M. G., Sanchez, A., \& Brussino, S. (2011). The Buss-Perry Aggression Questionnaire: Construct validity and gender invarianceamong Argentinean adolescents. International Journal of Psychological Research, 4(2), $30-37$.

The $\mathrm{A}$ and $\mathrm{B}$ models shown a bad fit according to $\chi^{2}$ statistic $\left(\mathrm{A}: \chi^{2}(297, N=371)=460.55, p<.00 ; \mathrm{B}\right.$ : $\left.\chi^{2}(366, N=371)=680.81, p<.00\right)$. Following the recommendations to consider multiple indicators, it was observed that both models presented a relatively bad or acceptable fit as other criteria of absolute fit; while an acceptable fit was observed according to comparative and parsimonious indexes (Table 2). In the A model the range of standardized regression coefficients was .32-.63 in factor 1 , and .29-.66 in factor 2. In the B model they ranged from .55 to .70 in physical aggression (except for item 24), .44 to .68 in verbal aggression, .27 to .67 in anger, and .35 to .63 in hostility. The $\mathrm{B}$ model showed an adequate fit according to all considered indexes, including the $\chi^{2}$ statistic $\left(\chi^{2}(47, N\right.$ $=371)=63.42, p<.055)$ (Table 2). In this model, standardized regression weights ranged from .53 to .71 in physical aggression, .47 to .65 in verbal aggression, .31 to .69 in anger, and .40 to .66 in hostility.

Table 2.Goodness-of-fit indices for different models of the Aggression Questionnaire

\begin{tabular}{|c|c|c|c|c|c|c|c|c|c|c|c|}
\hline Model & $\chi^{2}$ & $\mathrm{df}$ & GFI & AGFI & SRMR & CFI & NNFI & RMSEA & PNFI & PGFI & AIC \\
\hline A- EFA & 460.55 & 297 & $\overline{0.92}$ & 0.89 & 0.049 & 0.98 & 0.97 & 0.038 & 0.79 & 0.72 & 614.07 \\
\hline B- Buss \& Perry (1992) & $680.81^{* *}$ & 366 & 0.90 & 0.88 & 0.051 & 0.97 & 0.96 & 0.042 & 0.83 & 0.76 & 739.26 \\
\hline C- Bry ant \& Smith (2001) & $63.42^{*}$ & 47 & 0.97 & 0.96 & 0.038 & 0.99 & 0.98 & 0.027 & 0.68 & 0.59 & 121.74 \\
\hline
\end{tabular}

Note. GFI: goodness of fit index; AGFI: adjusted GFI; SRMR: standardized root-mean-square residual; CFI: comparative fit index; NNFI: non-normed fit index; RMSEA: mean square error of approximation; PNFI: parsimony normed fit index; PGFI: parsimony goodness of fit index; AIC: Akaike information criteria.

${ }^{*} p<.06 .{ }^{* *} p<.00$.

\section{Internal consistency}

With regard to reliability, internal consistency was evaluated by means of Cronbach's alpha $(\alpha)$. Indices between .70 and .80 are considered good reliability estimates (Kaplan \& Sacuzzo, 2006), whereas it is acceptable a lower value (around .60) on scales that meet certain criteria (Loewenthal, 2001). In that sense, the A model showed good indices for the total scale, and also for subscales. The B and C models showed good indices for the total scale, while for subscales indices were good, acceptable or low (see Table 4).

\section{Gender invariance}

Confirmatory factor analyses were carried out for each considered model. Maximum likelihood method was used, and the same correlations between errors as those observed in previous models were allowed. Table 3 contains fit results for each model. The following indices were considered: $\chi^{2}$, CFI, RMSEA, and AIC. In order to compare nested models $\Delta$ CFI and $\Delta \chi^{2}$ criteria were used (Byrne \& Stewart, 2006, Cheung \&Rensvold, 2002). In the A model both structures showed an acceptable fit. While the results were similar when examining configural and metric invariance, $\Delta \chi^{2}$ and $\Delta$ CFI indicated opposite conclusions, according to the first invariance is not satisfied, and according to the second it is satisfied. In the B model results were similar to those observed in the $\mathrm{A}$ model. And in the $\mathrm{C}$ model not only both gender showed an adequate fit but both configural and metric invariance were supported. As expected, none of the models supported strong invariance, which means that latent means of men and women are different.

In order to compare men with women on each subscale and total scale $t$-tests were developed. Men showed higher values of physical aggression than women according to $\mathrm{B}(t(369)=2.95, p<.003, d=0.32)$ and $\mathrm{C}$ $(t(369)=-2.9, p<.004, d=0.32)$ models. Moreover, women showed higher values of anger according to the $\mathrm{B}$ model $(t(369)=2.22, \quad p<.027, d=0.24)$. However, the 
International Journal of Psychological Research, 2011.Vol. 4. No. 2.

ISSN impresa (printed) 2011-2084

ISSN electrónica (electronic) 2011-2079

effect size in both cases was small. No other gender differences were found (Table 4).

Table 3. Goodness-of-fit indices for different models of the Aggression Questionnaire.

\begin{tabular}{|c|c|c|c|c|c|c|c|}
\hline Model & $\chi^{2}$ & $\mathrm{gl}$ & CFI & RMSEA & AIC & $\Delta \chi^{2}$ & $\Delta \mathrm{CFI}$ \\
\hline \multicolumn{8}{|l|}{ A- EFA } \\
\hline Men & 408.87 & 297 & 0.95 & 0.046 & 542.73 & & \\
\hline Women & 424.02 & 297 & 0.97 & 0.039 & 566.59 & & \\
\hline Conf. Inv. & 832.89 & 594 & 0.97 & 0.042 & 1109.32 & & \\
\hline Metric Inv. & 905.88 & 645 & 0.96 & 0.041 & 1071.47 & $72.99^{*}$ & -0.01 \\
\hline $\begin{array}{l}\text { Strong Inv. } \\
\text { B- Buss \& } \\
\text { Perry (1992) }\end{array}$ & 1106.6 & 697 & 0.94 & 0.053 & 1280.93 & $200.72^{* * * *}$ & -0.02 \\
\hline Men & 507.9 & 366 & 0.94 & 0.047 & 609.3 & & \\
\hline Women & 559.22 & 366 & 0.96 & 0.046 & 683.88 & & \\
\hline Conf. Inv. & 1067.13 & 732 & 0.95 & 0.046 & 1293.18 & & \\
\hline Metric Inv. & 1118.52 & 762 & 0.95 & 0.046 & 1273.31 & $51.39^{* *}$ & 0 \\
\hline Strong Inv. & 1542.18 & 816 & 0.9 & 0.069 & 1765.21 & $423.66^{* * * *}$ & -0.05 \\
\hline \multicolumn{8}{|l|}{$\begin{array}{l}\text { C-Bryant \& } \\
\operatorname{Smith}(2001)\end{array}$} \\
\hline Men & 54.19 & 47 & 0.98 & 0.022 & 112.15 & & \\
\hline Women & 55.95 & 47 & 0.99 & 0.022 & 114.39 & & \\
\hline Conf. Inv. & 110.14 & 94 & 0.99 & 0.022 & 226.54 & & \\
\hline Metric Inv. & 123.26 & 103 & 0.99 & 0.026 & 221.67 & 13.12 & 0 \\
\hline Strong Inv. & 235.83 & 123 & 0.92 & 0.07 & 349.61 & $112.57^{* * * *}$ & -0.07 \\
\hline
\end{tabular}

\section{DISCUSSION}

This study examined psychometric properties of the Aggression Questionnaire in a sample of Argentinean adolescents. In general, results have shown a similar structure for men and women. Even though items appear be understood and answered in a similar way, different results were observed for each model and index considered. Reduced version of 12-items presented the best fit.

An initial exploratory factor analysis failed to replicate the 4-factor structure commonly reported; a 2factor model showed a better fit. As noted earlier, the 4factor structure has not always offered a good fit. For instance, Williams et al. (1996) found that a 2-factor structure presented a best fit for U.S. adult offenders. By other hand, some authors have considered excluding some problematic items (Harris, 1995; Meesters et al., 1996; Nakano, 2001). In particular, Santisteban et al. (2007) observed that items 3 and 24 had low factor loadings in a
Reyna, C., Lello, M.G., Sanchez, A., \& Brussino, S. (2011).The Buss-Perry Aggression Questionnaire: Construct validity and gender invariance among Argentinean adolescents. International Journal of Psychological Research, 4(2), $30-37$.

sample of Spanish preadolescents. Beyond that, it is remarked that not all studies have used the same extraction and rotation methods, consequently comparisons should be taken with caution.

Table 4. Internal consistency, means, standard deviations, and effect size estimates for different models of the Aggression Questionnaire.

\begin{tabular}{|c|c|c|c|c|c|c|}
\hline \multirow[t]{2}{*}{ Model } & \multirow[t]{2}{*}{$\alpha$} & \multicolumn{2}{|c|}{$\begin{array}{c}\text { Men } \\
(n=134)\end{array}$} & \multicolumn{2}{|c|}{$\begin{array}{l}\text { Women } \\
(n=237)\end{array}$} & \multirow[t]{2}{*}{$d$} \\
\hline & & $M$ & $S D$ & $M$ & $S D$ & \\
\hline \multicolumn{7}{|l|}{ A- EFA } \\
\hline Total & 0.883 & 70.09 & 18.18 & 70.38 & 19.38 & -0.02 \\
\hline Factor 1 & 0.853 & 34.81 & 10.46 & 33.13 & 12.01 & 0.15 \\
\hline \multicolumn{7}{|l|}{$\begin{array}{l}\text { B- Buss \& Perry } \\
\text { (1992) }\end{array}$} \\
\hline Total & 0.875 & 76.90 & 18.62 & 77.55 & 19.76 & -0.03 \\
\hline $\begin{array}{l}\text { Physical } \\
\text { Aggression }\end{array}$ & 0.779 & 24.07 & 7.38 & 21.59 & 7.99 & $0.32^{*}$ \\
\hline Verbal Aggression & 0.68 & 12.39 & 3.98 & 12.91 & 4.55 & -0.12 \\
\hline Anger & 0.671 & 18.80 & 5.49 & 20.59 & 5.86 & $-0.32^{*}$ \\
\hline \multicolumn{7}{|l|}{$\begin{array}{l}\text { C- Bryant \& } \\
\text { Smith (2001) }\end{array}$} \\
\hline Total & 0.776 & 30.66 & 8.94 & 31.25 & 9.33 & -0.06 \\
\hline $\begin{array}{l}\text { Physical } \\
\text { Aggression }\end{array}$ & 0.702 & 7.26 & 3.45 & 6.44 & 3.39 & $0.24^{*}$ \\
\hline Verbal Aggression & 0.552 & 6.82 & 2.67 & 7.04 & 2.91 & -0.08 \\
\hline Anger & 0.48 & 8.31 & 3.10 & 8.86 & 3.06 & -0.18 \\
\hline Hostility & 0.548 & 8.26 & 3.14 & 8.91 & 3.25 & -0.20 \\
\hline
\end{tabular}

Note. $\alpha$ : Cronbach's alpha. " $t$-values $p<0.05$.

The model obtained in the exploratory factor analysis and the original and shortened models of the Aggression Questionnaire were submitted to confirmatory factor analysis. In general, all three models presented a good fit. These results agree with the report of Morales et al. (2005), they indicated that both original and short forms of the Aggression Questionnaire presented a good fit in a heterogeneous sample of Spanish. Besides, studies with samples from other countries such as China, Canada and Greece showed that the short version offered a better fit (Maxwell, 2007; Tremblay \& Ewart, 2005; Vitoratou et al., 2009).

Regarding to internal consistence, good indices were obtained for most of full and subscales versions. As was expected, the short version showed the lowest values of internal consistency. In general, previous findings have reported good properties of internal consistency. However, some studies have found low indices in some dimensions

International Journal of Psychological Research 
International Journal of Psychological Research, 2011.Vol. 4. No. 2.

ISSN impresa (printed) 2011-2084

ISSN electrónica (electronic) 2011-2079

(Ang, 2007; Meesters et al., 1996; Morren \& Meesters, 2002; Ramirez, Andreu, \& Fujihara, 2001). For the short version, an obvious explanation is the limited number of items, while otherfactors such as culture or age can perhaps also explain those results.

These findings indicate that the structure of the Aggression Questionnaire appears to be similar for both men and women; items are similarly interpreted and answered. However, the short version appeared to show a slightly better fit. Furthermore, gender differences found are in line with what is mostly stated in the literature. Gender differences observed in only some dimensions highlights the multiple facets of aggression. There is considerable agreement on the differences in physical aggression, and these results supported it. However, differences in anger have been only sometimes reported. It suggests that the expression of cognitive and emotional component of aggression might be different across cultures and age.

The main limitation of this study was the sample size and the sampling method. This sample might not be representative of Cordoba adolescents. Hence, further studies should seek to obtain probabilistic and more heterogeneous samples, thereby to facilitate the generalizability.

This study was a first approximation to the psychometric properties of the Aggression Questionnaire among Argentinean adolescents. Considering the multiple relations of aggression to other variables such as academic performance, drug use and other personality constructs (e.g., sensation seeking and impulsivity) (Anderson \& Bushman, 2002), studies that address these relationships would provide evidence of predictive and convergent validity. In addition, taking into account the relatively good characteristics of the short version, and its advantages to be included within larger battery of items, it is recommendable to examine more in detail its properties. These findings highlighted the relevance of adapting instruments constructed or employed in countries with different cultures to the target population (Hambleton, 2001; Poortinga, 2000).

\section{REFERENCES}

Anderson, C. A. \& Bushman, B. J. (2002). Human aggression. Annual Review of Psychology, 53, 2751.

Andreu, J. M., Peña, M. E., y Graña, J. L. (2002). Adaptación psicométrica de la versión española del Cuestionario de Agresión. Psicothema, 14(2), 476-482.
Reyna, C., Lello, M. G., Sanchez, A., \& Brussino, S. (2011). The Buss-Perry Aggression Questionnaire: Construct validity and gender invarianceamong Argentinean adolescents. International Journal of Psychological Research, 4(2), $30-37$.

Ang, R. P. (2007). Factor structure of the 12-item aggression questionnaire: Further evidence from Asian adolescent samples. Journal of Adolescence 30(4), 671-685.

Archer, J. (2004). Sex differences in aggression in realworld settings: A meta-analytic review. Review of General Psychology, 8(4), 291-322.

Brown, T. A. (2006). Confirmatory factor analysis for applied research. New York: The Guilford Press.

Bryant, F. B. \& Smith, B. D. (2001).Refining the architecture of aggression: A measurement model of the Buss-Perry Aggression Questionnaire. Journal of Research in Personality, 35(2) 138-167.

Buss, A. H. \& Perry, M. (1992). The Aggression Questionnaire. Journal of Personality and Social Psychology, 63(3), 452-459.

Byrne, B. M. \& Stewart, S. M. (2006). The MACS approach to testing for multigroup invariance of a second-order structure: A walk through the process. Structural Equation Modeling, 13(2), 287-321.

Byrne, B. M. \& Watkins, D. (2003). The issue of measurement invariance revisited. Journal of Cross-cultural Psychology, 34(2), 155-175.

Castillón, D. A., Ortiz, P. A., y Vieco, F. (2004). Cualidades paramétricas del cuestionario de agresión (AQ) de Buss y Perry en estudiantes universitarios de la ciudad de Medellín (Colombia). Revista Facultad de Salud Pública, 22(2), 49-61.

Cheung, G. W. \& Rensvold, R. B. (2002). Evaluating goodness-of-fit indexes for testing measurement invariance. Structural Equation Modeling, 9(2), 233-255.

Fossati, A., Maffei, C., Acquarini, E., \& Di Ceglie, A. (2003). Multigroup confirmatory component and factor analyses of the Italian version of the Aggression Questionnaire. European Journal of Psychological Assessment, 19(1), 54-65.

Gallardo, D., Kramp, U., García, C., Pérez, M., \& Andrés, A. (2006). Assessing aggressiveness quickly and efficiently: the Spanish adaptation of Aggression Questionnaire-Refined version. European Psychiatry, 21(7), 487-494.

García-León, A., Reyes, G.A., Vila, J., Pérez, N., Robles, H., \& Ramos, M. M. (2002). The Aggression Questionnaire: A validation study in student samples. Spanish Journal of Psychology, 5(1), 4553.

Gerevich, J., Bácskai, E., \& Czobor, P. (2007). The generalizability of the Buss-Perry Aggression Questionnaire. International Journal of Methods in Psychiatric Research, 16(3), 124-136. 
International Journal of Psychological Research, 2011.Vol. 4. No. 2.

ISSN impresa (printed) 2011-2084

ISSN electrónica (electronic) 2011-2079

Hair, J. F., Black, W. C., Babin, B. J., \& Anderson, R. E. (2009). Multivariate data analysis (7th ed.). Upper Saddle River, NJ: Prentice Hall.

Harris, J. A. (1995). Confirmatory factor analysis of the aggression questionnaire. Behaviour Research and Therapy, 33(8), 991-993.

Hambleton, R. K. (2001). The next generation of the ITC test translation and adaptation guidelines. European Journal of Psychological Assessment, 17, 164-172.

Hu, L. \& Bentler, P. M. (1999). Cutoff criteria for fit indexes in covariance structure analysis: Conventional criteria versus new alternatives. Structural Equation Modeling, 6(1), 1-55.

Jöreskog, K. \& Sörbom, D. (2006). LISREL 8.80 for Windows [Computer Software].Lincolnwood, IL: Scientific Software International, Inc.

Kaplan, R. M. \& Saccuzzo, D. P. (2006). Pruebas psicológicas: Principios, aplicaciones y temas (6a ed.). Mexico: Thoms on Learning.

Loewenthal, K. M. (2001). An introduction to psychological tests and scales (2nd ed.). London: Psychology Press.

Maxwell, J. P. (2007). Development and preliminary validation of a Chinese version of the Buss-Perry Aggression Questionnaire in a population of Hong Kong Chinese. Journal of Personality Assessment, 88(3), 284-294.

Meesters, C., Muris, P., Bosma, H., Schouten, E., \& Beuving, S. (1996). Psychometric evaluation of the Dutch version of the Aggression Questionnaire.Behaviour Research and Therapy, 34(10), 839-843.

Morales, F., Codorniu, M. J., y Vigil, A. (2005). Características psicométricas de las versiones reducidas del Cuestionario de Agresividad de Buss y Perry. Psicothema, 17(1), 96-100.

Morren, M. \& Meesters, C. (2002). Validation of the Dutch version of the Aggression Questionnaire in adolescent male offenders.Aggressive Behavior, 28(2), 87-96.

Nakano, K. (2001). Psychometric evaluation on the Japanese adaptation of the Aggression Questionnaire. Behaviour Research and Therapy, 39(7), 853-858.

Poortinga, Y. H. (2000). Cross-cultural test adaptation. En A. E. Kazdin (Ed.), Encyclopedia of psychology (pp. 369-371). Washington, DC: American Psychological Association.

Ramirez, J. M., Andreu, J. M., \& Fujihara, T. (2001). Cultural and sex differences in aggression: A comparison between Japanese and Spanish students using two different inventories. Aggressive Behavior, 27(4), 313-322.
Reyna, C., Lello, M.G., Sanchez, A., \& Brussino, S. (2011).The Buss-Perry Aggression Questionnaire: Construct validity and gender invariance among Argentinean adolescents. International Journal of Psychological Research, 4(2), $30-37$.

Rodríguez, J. M., Peña, E., y Graña, J. L. (2002). Adaptación psicométrica de la versión española del Cuestionario de Agresión. Psicothema, 14(2), 476-482.

Santisteban, C. \& Alvarado, J. M. (2009). The Aggression Questionnaire for Spanish preadolescents and adolescents: AQ-PA. The Spanish Journal of Psychology, 12(1), 320-326.

Santisteban, C., Alvarado, J. M., \& Recio, P. (2007). Evaluation of a Spanish version of the Buss and Perry aggression questionnaire: Some personal and situational factors related to the aggression scores of young subjects. Personality and Individual Differences, 42(8), 1453-1465.

Schumacker, R. E. \& Lomax, R. G. (2004). A beginner's guide to structural equation modeling (2nd ed.). Mahwah, NJ: Lawrence Erlbaum Associates.

Sierra, J. C. \& Gutiérrez, Q. J. R. (2007).Validación de la versión española del Cuestionario de Agresión de Buss-Perry en Estudiantes Universitarios Salvadoreños. Psicología y Salud, 17(1), 303-313

Sommantico, M., Osorio, M., Parrello, S., De Rosa, B., \& Donizzetti, A. R. (2008). Local validation study of the Italian version of the Aggression Questionnaire (AQ) in Southern Italy.8th Alps-Adria Psychology Conference. Ljubljana, Slovenia.

Tremblay, P. F. \& Ewart, L. A. (2005).The Buss and Perry Aggression Questionnaire and its relations to values, the Big Five, provoking hypothetical situations, alcohol consumption patterns, and alcohol expectancies. Personality and Individual Differences, 38(2), 337-346.

Vitoratou, S., Ntzoufras, I., Smyrnis, N., \& Stefanis, N. C. (2009). Factorial composition of the Aggression Questionnaire: A multi-sample study in Greek adults. Psychiatry Research, 168(1), 32-39.

Von Collani, G. \& Werner, R. (2005). Self-related and motivational constructs as determinants of aggression.An analys is and validation of a German version of the Buss-Perry aggression questionnaire.Personality and Individual Differences, 38(7), 1631-1643.

Williams, T. Y., Boyd, J. C., Cascardi, M. A., \& Poythress, N. (1996).Factor structure and convergent validity of the Aggression Questionnaire in an offender population. Psychological Assessment, 8(4), 398403.

\section{APPENDIX}

The following items were the same to those employed in Andreu et al. (2002), and Santisteban and Alvarado (2009): $3^{*}, 4,14^{*}, 17,18,20,25^{*}, 26,27,28,29$. Items $11^{*}$ and 24 were those presented by Andreu et al (2002). The next items were the same to those used in Santisteban and 
Alvarado (2009): 1, 2, 5, 7*, 8, 9, 10, 12, 13, 15, 16, 19, 21 ${ }^{*}$, $22^{*}, 23$. Items with asterisk were subtly modified: $3,7,22=$ enfado replaced by $(\rightarrow)$ enojo; $11=$ enfadado $\rightarrow$ enojado; 14 $=$ remediar $\rightarrow$ evitar; $21=$ enfada $\rightarrow$ molesta; $25=$ genio $\rightarrow$ humor. 